\title{
Breast cancer in a cohort of human immunodeficiency virus (HIV)-infected women from Rio de Janeiro, Brazil: a cases series report and an incidence rate estimate
}

\begin{abstract}
Highly active antiretroviral therapy (HAART) has changed the morbidity pattern affecting HIV-infected individuals to include non-AIDS-defining cancers. We describe the breast cancer cases occurring in a cohort of $860 \mathrm{HIV}$-infected women followed in Rio de Janeiro, Brazil, and estimate the incidence rate of breast cancer for this population. Nine cases were identified; median age at diagnosis was 46 years. Median survival after breast cancer diagnosis was 12 months. Breast cancer diagnosis was made within 2 to 15 years of HIV-infection diagnosis. At breast cancer diagnosis, CD4 counts ranged from 135 to 782 cells $/ \mathrm{mm}^{3}$; six women were receiving HAART. Histological analysis indicated infiltrating ductal carcinoma in all cases. The incidence rate of breast cancer was 133 cases per 100,000 personsyear. Patients from our case series were late diagnosed with breast cancer and thus suffered from worse prognosis. Strategies targeting earlier diagnosis and prompt initiation of treatment are needed.
\end{abstract}

Keywords: HIV; breast neoplasms; case reports; incidence.

\section{INTRODUCTION}

Worldwide, since the introduction of highly active antiretroviral therapy (HAART), the life expectancy of HIV-infected individuals has increased while the incidence of both opportunistic infections and AIDS-defining cancers has dramatically decreased. ${ }^{1-3}$ A new morbidity pattern has emerged which includes complications associated with treatment toxicity, coinfections (in particular hepatitis B and C), cardiovascular diseases, bacterial infections and non-AIDS-defining cancers. ${ }^{4,5}$

Breast cancer, a non-AIDS-defining malignancy, has not been shown to occur with greater incidence among HIV-infected women when compared to the general female population. ${ }^{3,6-8}$ Although it has been suggested that breast cancer in the setting of HIV disease has a more aggressive clinical course and poorer outcome, ${ }^{9,10}$ these findings are controversial. $^{11,12}$

Treatment decisions in patients with HIV and breast cancer are complicated by the risk of immunological and hematological toxicities and by the complex drug interactions between chemotherapeutic agents and HAART. There is also the possibility for the progression of HIV disease in the setting of cytotoxic therapy. Breast cancer case series have been reported in the literature, ${ }^{10-14}$ but more information is needed in order to better understand the interactions between the two diseases.

In Brazil, breast cancer is currently the most common malignancy among women, with 49,400 new cases expected to occur in 2009. ${ }^{15}$ Most cases are late diagnosed thus limiting the treatment options. ${ }^{16,17}$ To date, there are no reports of breast cancer case series or breast cancer incidence for HIV-infected women from Brazil or Latin America as a whole. In this study, we report on the breast cancer cases occurring in a cohort of HIV-infected women followed at Rio de Janeiro, Brazil. We give information on the socio-demographic, clinical, pathological and survival characteristics. Also, we estimate the incidence rate of breast cancer within the cohort.

\section{MATERIALS AND METHODS}

To study the natural history of HIV infection in women, a prospective open cohort was established at the Instituto de Pesquisa
Authors

Angela Cristina Vasconcelos de Andrade ${ }^{1}$

Paula Mendes Luz ${ }^{2}$ Valdiléa Gonçalves Veloso² Sandra Wagner Cardoso ${ }^{1}$ Ronaldo Ismerio Moreira ${ }^{3}$ Beatriz Grinsztejn ${ }^{2}$ Ruth Khalili Friedman ${ }^{2}$

${ }^{1} \mathrm{MD}, \mathrm{MSc}$, Instituto de Pesquisa Clínica Evandro Chagas, Fundação Oswaldo Cruz, RJ, Brazil ${ }^{2} \mathrm{MD}, \mathrm{PhD}$, Instituto de Pesquisa Clínica Evandro Chagas, Fundação Oswaldo Cruz, RJ, Brazil

${ }^{3} \mathrm{BSc}$, Instituto de Pesquisa Clínica Evandro Chagas, Fundação Oswaldo Cruz, RJ, Brazil

Submitted on: 01/03/2011 Approved on: 02/06/2011

Correspondence to: Beatriz Grinsztejn Avenida Brasil, 4365 Manguinhos

21040-360,

Rio de Janeiro, RJ

Brazil

beatriz.grinsztejn@gmail.com

We declare no conflict of interest.

(이릴 Elsevier Editora Ltda. All rights reserved. 
Clínica Evandro Chagas (IPEC), Fundação Oswaldo Cruz, Rio de Janeiro, Brazil. From the cohort's onset in May 1996 up until September 2009, 860 women have enrolled the cohort after signing an informed consent that inquired on willingness to participate and attend all medical appointments. Cohort procedures and baseline information on the prevalence of sexually transmitted infections, including human papillomavirus virus infection, and of squamous intra-epithelial cervical lesions and its determinants have been published. ${ }^{18-20}$ Briefly, biannual medical appointments evaluate gynecological signs and symptoms, pelvic examination with specimen collection, breast examination, sexual and behavioral practices, and reproductive counseling. For all cases, diagnosis was confirmed through histological analysis conducted by pathologists at either Instituto Fernandes Figueira, a women's and children's reference center of Fundação Oswaldo Cruz or the National Institute of Cancer. The TNM system for staging malignant tumors was used. It gives information on the extent of the primary tumor $(\mathrm{T})$, of regional lymph node $(\mathrm{N})$ metastasis, and of distant metastasis (M). Treatment was individualized, according to disease staging, tumor hormonal receptor susceptibility, patient's clinical condition and comorbidities. CD4+ T-cell count (Becton Dickinson FACScan) were obtained from the participant's medical record. CD4+ T-cell count at breast cancer diagnosis was defined as the closest to the date of breast cancer diagnosis. Nadir CD4+ T-cell count was defined as the lowest since HIV diagnosis up until breast cancer diagnosis. Individuals were considered under antiretroviral therapy if they were receiving treatment at breast cancer diagnosis.

\section{RESULTS}

Nine cases of breast cancer have occurred. Median age at breast cancer diagnosis was 46 years (range 36-59 years). Two patients reported family history of breast cancer and five reported smoking. All patients reported previous pregnancies, four women did not breastfeed. Breast cancer diagnosis was made within 2 to 15 years of HIV-infection diagnosis. At breast cancer diagnosis, CD4+ T-cell counts ranged from 135 to 782 cells $/ \mathrm{mm}^{3}$; six women were receiving HAART. Histological analysis indicated infiltrating ductal carcinoma in all cases. For two patients surgical treatment was not possible due to poor clinical conditions deriving from acquired immunodeficiency syndrome (AIDS). Five deaths have occurred, two due to AIDS-related conditions, two due to breast cancer, and one of unknown cause. Median survival after breast cancer diagnosis was of 12 months (range: 6-46 months).

During the study period, 860 women enrolled into the cohort, comprising 6,745 persons/year of follow-up time, which yields an incidence rate of breast cancer among HIV-infected women of 0.00133 cases per persons/year, or 133 cases per 100,000 persons/year.

Following, we describe the nine cases of breast cancer. Two tables accompany these descriptions giving the following information: socio-demographic and general risk factor characteristics (Table 1), and HIV infection and breast cancer disease characteristics (Table 2).

\section{Case 1}

Case 1 was a 50 -year old woman, non-white, menarche at 14 , first pregnancy at 27 , four pregnancies, having breastfed. She had a history of hypertension and hormone use.

Table 1. Socio-demographic and risk factor characteristics for each case reported

\begin{tabular}{|c|c|c|c|c|c|c|c|c|c|c|c|}
\hline & $\begin{array}{c}\text { Age } \\
\text { (years) }\end{array}$ & Race & Smoking & $\begin{array}{c}\text { Alcohol } \\
\text { use }\end{array}$ & $\begin{array}{l}\text { Hyper- } \\
\text { tension }\end{array}$ & Obesity & $\begin{array}{c}\text { Age at } \\
\text { first } \\
\text { pregnancy } \\
\text { (years) }\end{array}$ & $\begin{array}{c}\text { Number } \\
\text { of } \\
\text { preg- } \\
\text { nancies }\end{array}$ & $\begin{array}{c}\text { Reported } \\
\text { breast- } \\
\text { feeding }\end{array}$ & $\begin{array}{c}\text { Hormone } \\
\text { use } \\
\text { (> } 5 \text { years) }\end{array}$ & $\begin{array}{l}\text { Family } \\
\text { history } \\
\text { of } \mathrm{BrCa}\end{array}$ \\
\hline Case 1 & 50 & Non-white & No & No & Yes & No & 27 & 4 & Yes & Yes & No \\
\hline Case 2 & 38 & Non-white & No & No & Yes & Yes & 19 & 4 & Yes & No & No \\
\hline Case 3 & 46 & White & No & No & Yes & No & 19 & 8 & Yes & No & No \\
\hline Case 4 & 43 & Non-white & Yes & Yes & No & No & 28 & 3 & No & Yes & Yes \\
\hline Case 5 & 44 & White & No & N/A & No & No & 23 & 2 & Yes & No & No \\
\hline Case 6 & 36 & White & Yes & $\mathrm{N} / \mathrm{A}$ & No & No & 21 & 4 & No & Yes & No \\
\hline Case 7 & 48 & White & Yes & No & Yes & No & 20 & 4 & No & No & Yes \\
\hline Case 8 & 54 & White & Yes & Yes & Yes & No & 37 & 1 & No & Yes & No \\
\hline Case 9 & 59 & Non-white & Yes & Yes & Yes & No & 23 & 3 & Yes & N/A & No \\
\hline
\end{tabular}

N/A, not available; BrCa, breast cancer. 


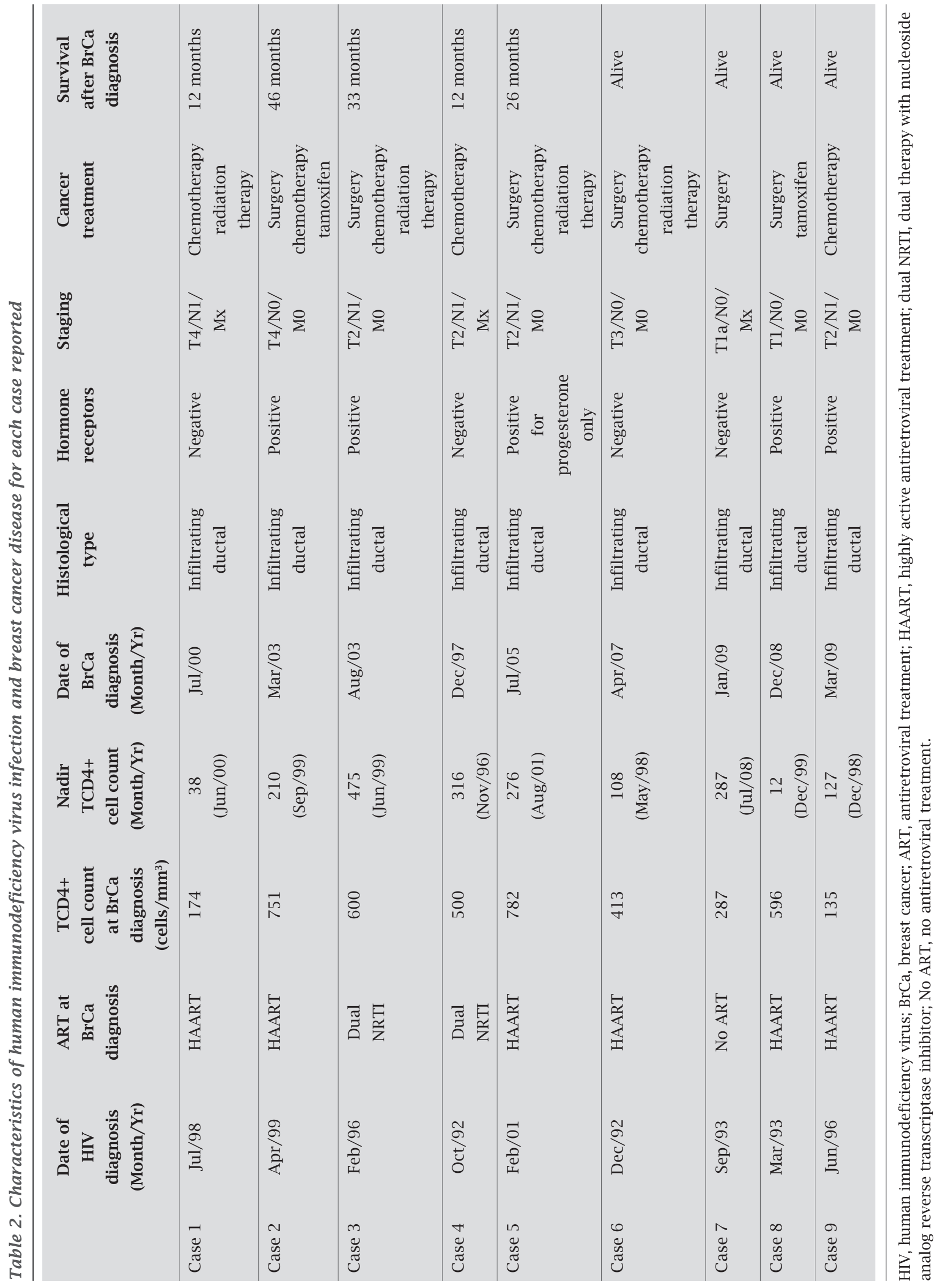


No family history of breast cancer was reported. HIV diagnosis occurred in July 1998. Two years after HIV diagnosis, physical examination revealed a lump of 6.0 $\mathrm{cm}$ at its larger diameter, located in the upper outer quadrant of her right breast, adherent to the skin, and papillae eversion. There was a hard lymph node, painless and mobile in the ipsilateral axilla. Histopathological study showed infiltrating ductal carcinoma by core biopsy. Staging was T4/N1/Mx; the tumor was hormone receptor negative. At breast cancer diagnosis, the patient was in use of HAART and her CD4+ T-cell count was 174 cells $/ \mathrm{mm}^{3}$.

Chemotherapy was initiated and substituted by radiation therapy due to concomitant opportunistic infection. Surgery was never performed due to lack of clinical conditions. HIV disease progressed to death due to AIDS 12 months after cancer diagnosis, with no evidence of metastasis.

\section{Case 2}

Case 2 was a 38 -year old woman, non-white, menarche at 12 , first pregnancy at 19 , four pregnancies, having breastfed. She was obese and had hypertension. No family history of breast cancer was reported. HIV-infection was diagnosed in April 1999. Four years after HIV diagnosis, she developed a nodule in the upper outer quadrant of her left breast which, at physical examination, had $2.5 \mathrm{~cm}$ at its larger diameter, was hard and not mobile. There was no palpable axillary lymph node. Histopathological study showed infiltrating ductal carcinoma. Staging was T4/N0/M0; the tumor was hormone receptor positive. At breast cancer diagnosis, she was receiving HAART and her CD4+ T-cell count was 751 cells $/ \mathrm{mm}^{3}$. She was submitted to mastectomy and axillary dissection, with lack of involvement of the 22 lymph nodes resected. She received chemotherapy and tamoxifen. Disease progressed to liver and pulmonary metastasis with death occurring 46 months after breast cancer diagnosis.

\section{Case 3}

Case 3 was a 46 -year old woman, white, menarche at 13, first pregnancy at 19, eight pregnancies, having breastfed. No family history of breast cancer was reported. HIV-infection was diagnosed in February 1996. Eight years after HIV diagnosis she developed a painless nodule in the upper inner quadrant of her right breast which, at physical examination, had $3.0 \mathrm{~cm}$ at its larger diameter, was hard and mobile. There were $1.5 \mathrm{~cm}$ lymph nodes, mobiles, fibroelastic, painless, and bilateral in axillary area. Histopathological study showed infiltrating ductal carcinoma by core biopsy. Staging was $\mathrm{T} 2 / \mathrm{N} 1 / \mathrm{M} 0$; the tumor was hormone receptor positive. At breast cancer diagnosis, she was receiving dual NRTI and her CD4+ T-cell count was 600 cells $/ \mathrm{mm}^{3}$. She was submitted to mastectomy and axillary dissection, presenting in- volvement of 9 of the 21 lymph nodes resected. She received chemotherapy and radiation therapy. She abandoned breast cancer treatment and died of an unknown cause 33 months after breast cancer diagnosis.

\section{Case 4}

Case 4 was a 43-year old woman, non-white, menarche at 13, first pregnancy at 28 , three pregnancies, not having breastfed. She reported drinking, smoking (20 cigarettes/day), and hormonal use for more than five years. There was a family history of breast cancer (maternal aunt). HIV-infection was diagnosed in October 1992. Five years after HIV diagnosis she developed a nodule in her right breast which, at physical examination, had $3.0 \mathrm{~cm}$ at its larger diameter, was hard and mobile. In two months the tumor grew to $5.0 \mathrm{~cm}$, with a $2.0 \mathrm{~cm}$ ipsilateral axillary lymph node. Fine needle aspiration yielded infiltrating ductal carcinoma, confirmed by core biopsy. Staging was T2/N1/Mx; the tumor was hormone receptor negative. At breast cancer diagnosis, she was receiving dual NRTI, and her CD4+ T-cell count was 500 cells $/ \mathrm{mm}^{3}$. She received chemotherapy; a scheduled subsequent surgery was not performed due to lack of clinical conditions. The patient died 12 months after the breast cancer diagnosis, due to opportunistic infections and chemotherapy toxicity.

\section{Case 5}

Case 5 was a 44 -year old woman, white, menarche at 13 , first pregnancy at 23 , two pregnancies, having breastfed. No family history of breast cancer was reported. HIV-infection was diagnosed in February 2001. Four years after HIV diagnosis she developed a nodule in the lower inner quadrant of her right breast which, at physical examination, had $2.0 \mathrm{~cm}$ at its larger diameter, was hard and mobile. There were no palpable lymph nodes. Core biopsy was performed yielding infiltrating ductal carcinoma. Staging was T2/N1/M0; the tumor was hormone receptor positive. At breast cancer diagnosis, she was receiving HAART, and her CD4+ T-cell count was $782 \mathrm{cells} / \mathrm{mm}^{3}$. She underwent quadrantectomy with axillary resection one month after breast cancer diagnosis. One year later, radical mastectomy was performed, and she received chemotherapy and radiation therapy. She later developed brain metastasis and died 26 months after breast cancer diagnosis.

\section{Case 6}

Case 6 was a 36-year old woman, white, menarche at 14, first pregnancy at 21 , four pregnancies, not having breastfed. She reported smoking (23 years, 20 cigarettes/day), hormone use, and no family history of breast cancer. HIV-infection was diagnosed in December 1992. Fifteen years later she reported a palpable nodule near the nipple of her right breast which, at physical examination, had $2.5 \mathrm{~cm}$ at its larger diameter, was painless and not mobile. There were no palpable axillary lymph nodes. Breast ultrasound 
scan revealed two bilateral solid nodules. A core biopsy was performed in the right breast nodule yielding infiltrating ductal carcinoma. Staging was T3/N0/M0; the tumor was hormone receptor negative. At breast cancer diagnosis, she was receiving HAART, and her CD4+ T-cell count was 413 cells $/ \mathrm{mm}^{3}$. She received chemotherapy, was submitted to surgery and later treated with chemotherapy and radiation therapy. Additional exams did not show metastasis. As of September 2009 she was alive and without evidence of breast cancer disease or metastasis.

\section{Case 7}

Case 7 was a 48 -year old woman, white, menarche at 9 , first pregnancy at 20, four pregnancies, not having breastfed. She reported smoking ( 25 years, 20 cigarettes/day), hypertension and family history of breast cancer (mother). HIV-infection was diagnosed in September 1993. In 2008 she performed a mammography that indicated category 5 BIRADS (Breast Imaging Reporting and Data System) result, with a normal clinical exam. A puncture biopsy was performed in the left breast yielding infiltrating ductal carcinoma. Staging was T1a/N0/Mx; the tumor was hormone receptor negative. At breast cancer diagnosis, she was not under antiretroviral treatment, and her CD4+ T-cell count was 287 cells $/ \mathrm{mm}^{3}$. She was submitted to surgery in March 2009; there was no need for chemotherapy or radiation therapy. As of September 2009 she was alive and without evidence of breast cancer disease or metastasis.

\section{Case 8}

Case 8 was a 54-year old woman, white, menarche at 9 , first pregnancy at 37 , one pregnancy, not having breastfed. She reported hypertension, smoking (33 years, 40 cigarettes/day) and hormone use; no family history of breast cancer. HIVinfection was diagnosed in March 1993. Fifteen years later, she performed a mammography that indicated category 5 BIRADS result, with a normal clinical exam. A puncture biopsy was performed in her right breast yielding infiltrating ductal carcinoma. Staging was T1/N0/M0; the tumor was hormone receptor positive. At breast cancer diagnosis, she was receiving HAART, and her $\mathrm{CD} 4+\mathrm{T}$-cell count was 596 cells $/ \mathrm{mm}^{3}$. She was submitted to mastectomy in March 2009, and is currently using tamoxifen. As of September 2009 she was alive and without signs of breast cancer disease or metastasis.

\section{Case 9}

Case 9 was a 59-year old woman, non-white, menarche at 11 , first pregnancy at 23 , three pregnancies, having breastfed. She reported smoking (35 years, 40 cigarettes/day), hypertension, and no family history of breast cancer. HIV-infection was diagnosed in June 1996. Thirteen years later, a breast lump of $3.0 \mathrm{~cm}$, with irregular borders, hardened, mobile and painless was noted in the lower outer quad- rant of the right breast with no palpable axillary lymph nodes. A mammography performed indicated category 4 BIRADS. Core biopsy was performed yielding infiltrating ductal carcinoma. Staging was T2/N1/M0. At breast cancer diagnosis, she was receiving HAART, and her CD4+ T-cell count was $135 \mathrm{cells} / \mathrm{mm}^{3}$. The treatment proposed was chemotherapy and subsequent surgery evaluation. As of September 2009, she had held two cycles of chemotherapy and the analysis of the tumor hormone receptor susceptibility is in progress.

\section{DISCUSSION}

The impact of HAART on the HIV epidemic includes greater life expectancy, a decreased risk of AIDS-defining cancers, and an increased risk of some non-AIDS-defining cancers. ${ }^{3,21,22}$ Breast cancer incidence has not been shown to be higher among HIV-infected individuals..$^{21,22}$ Among women, a pattern of decreasing risk of breast cancer has been shown with increasing time since AIDS diagnosis. ${ }^{23}$ Among men and women, a statistically significant decrease in the incidence of breast cancer has been observed following the AIDS epidemic in Tanzania. ${ }^{24}$ In France, the incidence of breast cancer was significantly lower in HIV-infected women than in the French general population $^{7,8}$ This apparent deficit in breast cancer cases may be explained by underreporting or competing mortality. In the United States, the deficit of breast cancer cases among women followed in the Women's Interagency HIV Study is explained by an overall lower frequency of established risk factors. ${ }^{25,26}$

In this study, we estimated an incidence rate of breast cancer among HIV-infected women that is similar to that observed in the general female population of Brazil. Recently, the Brazilian National Cancer Institute estimated an incidence rate of breast cancer of 120 cases per 100,000 people/year for the city of Rio de Janeiro. ${ }^{15}$ The prolonged survival and aging of HIV-infected patients together with the decreasing mortality derived from opportunistic infections may explain the similar incidence rates.

A more comprehensive understanding of the impact of HIV disease on breast cancer incidence and mortality requires further studies. Breast cancer series in HIV-infected individuals are still limited. ${ }^{10-14}$ The largest series reported to date describes 20 cases among women. ${ }^{12}$ In the latter, the median survival time from diagnosis was of 2.2 years. In our series, we observed a median survival time of 12 months. The clinical course of breast cancer in the setting of HIV infection might be worse than in the non-HIV patient due to the inability to deliver full doses of systemic anti-cancer therapies. Indeed, the presence of HIV infection has been shown to significantly influence the toxicity of chemotherapy. ${ }^{12}$ It is also possible that chemotherapy can adversely impact on the natural history of HIV. 
Several risk factors for breast cancer have been described; the most well-known are age over 35 years, family history (in particular mother or sister), pre-menopause, history of atypical hyperplasia or lobular carcinoma in situ, and documented genetic susceptibility (BRCA 1 and 2 mutation). ${ }^{27,28}$ Factors related to intense and prolonged estrogen exposition, including null parity, ovulatory dependent sterility, early menarche, late menopause, first pregnancy after 34 years of age, chronic use of hormones for more than five years are important risk factors. ${ }^{27,28}$ Lifestyle related factors are also suggested to influence breast cancer risk, such as obesity, smoking, no physical activity, and alcohol consumption..$^{28}$ Most likely, for our scenario, the prevalence of these risk factors is not different among HIV-infected women and thus the incidence of breast cancer should also be similar. Indeed, some of these risk factors were observed among the women composing our case series. All were older than 35 years of age, two reported family history of breast cancer, five reported smoking, and four reported prolonged hormone use.

Although the women in this cohort were followed with bi-annual gynecological evaluations that included breast examination, the majority of patients were late diagnosed. Patients in our case series presented with advanced staging, and, hence, worse prognosis. This may be related to the delay in scheduling the appropriate procedures needed to confirm suspicious lesions. The end result of the late diagnosis is poor survival. ${ }^{29}$ Late presentation coupled with poor survival is a problem in many parts of the world. ${ }^{30}$ In Brazil, breast cancer diagnosis occurs late in the disease course, and a significant part of this delay is related to the fragmentation and inappropriateness of the available health services. ${ }^{17}$ A study performed with data from 89 hospitals specialized in cancer treatment and seven isolated services for chemotherapy and radiotherapy, covering altogether 43,442 breast cancer cases showed that between 1995 and 2002, 87.7\% women were late diagnosed with breast cancer. ${ }^{31}$ In Brazil, since 1979, breast cancer is the leading cause of death due to cancer among women. The high mortality rate for breast cancer in Brazil is mostly related to the delay in the diagnosis and implementation of adequate treatment. ${ }^{32}$ Therefore, all efforts to expedite the evaluation, diagnosis and staging of potential cases should be made so that the usual delay in breast cancer diagnosis does not further impair the prognosis of the patients.

Late diagnosis may also be explained by poor screening. In fact, differential screening access and practices among HIV-infected individuals is another explanation for the decreased incidence of breast cancer among the HIV-infected. Those with HIV, particularly injection drug users and the poor, are less likely to be regularly screened for cancers. Indeed, screening among HIV-infected women enrolled in the Wom- en's Interagency HIV Study was lower than that reported in the overall United States population. ${ }^{33}$ Hence, more subclinical disease may be detected among those without HIV, which would result in an apparent increased incidence. In Brazil, access to mammography is still limited through the public health system. Our cohort of HIV-infected women are unique in that they have regular contact with gynecologists and may, therefore, have received more recommendations to seek breast cancer screening. In fact, the close monitoring of HIV-infection and treatment represents an opportunity to institute other recommended health interventions. ${ }^{33}$ As with the general population, screening strategies targeting early diagnosis and treatment of breast cancer will positively impact the survival of these patients.

The accelerated aging process of HIV-infected individuals should prompt the discussion of earlier mammography screening for these women, as they might be subject to a risk of developing breast cancer earlier in life when compared to the general population. In our case series, the median age of the women diagnosed with breast cancer was 46 years, while in the general population the incidence rate of breast cancer increases with age, reaching its highest levels at ages 65-70 years. ${ }^{15}$ Focused efforts on increasing awareness of breast cancer and providing easy access to cancer screening are key strategies to curb breast cancer occurrence among the HIV-infected. Also, treatment must include close monitoring of the viral load, chemotherapy-related toxicity, and prophylactic granulocyte colony stimulating factor (G-CSF)support. Physicians treating women with breast cancer and HIV infection must be aware of the complex interactions of the two therapies.

\section{ACKNOWLEDGEMENTS}

Ethics: The IPEC Institutional Review Board approved the study; research was conducted according to the Declaration of Helsinki.

\section{REFERENCES}

1. Crum-Cianflone N, Hullsiek KH, Marconi V et al. Trends in the incidence of cancers among HIV-infected persons and the impact of antiretroviral therapy: a 20-year cohort study. AIDS 2009; 23:41-50.

2. Sackoff JE, Hanna DB, Pfeiffer MR, Torian LV. Causes of death among persons with AIDS in the era of highly active antiretroviral therapy: New York City. Ann Intern Med 2006; 145:397-406.

3. Silverberg MJ, Abrams DI. AIDS-defining and non-AIDSdefining malignancies: cancer occurrence in the antiretroviral therapy era. Curr Opin Oncol 2007; 19:446-51.

4. Marin B, Thiebaut R, Bucher HC et al. Non-AIDS-defining deaths and immunodeficiency in the era of combination antiretroviral therapy. AIDS 2009; 23:1743-53. 
5. Mitsuyasu RT. Non-AIDS-defining malignancies in HIV. Top HIV Med 2008; 16:117-21.

6. Goedert JJ, Schairer C, McNeel TS, Hessol NA, Rabkin CS, Engels EA. Risk of breast, ovary, and uterine corpus cancers among 85,268 women with AIDS. Br J Cancer 2006; 95:642-8.

7. Herida M, Mary-Krause M, Kaphan R et al. Incidence of nonAIDS-defining cancers before and during the highly active antiretroviral therapy era in a cohort of human immunodeficiency virus-infected patients. J Clin Oncol 2003; 21:3447-53.

8. MbulaiteyeSM, Biggar RJ, Goedert JJ, Engels EA. Immune deficiency and risk for malignancy among persons with AIDS. J Acquir Immune Defic Syndr 2003; 32:527-33.

9. Pantanowitz L, Connolly JL. Pathology of the breast associated with HIV/AIDS. Breast J 2002; 8:234-43.

10. Voutsadakis IA, Silverman LR. Breast cancer in HIV-positive women: a report of four cases and review of the literature. Cancer Invest 2002; 20:452-7.

11. Oluwole SF, Ali AO, Shafaee Z, DePaz HA. Breast cancer in women with HIV/AIDS: report of five cases with a review of the literature. J Surg Oncol 200; 89:23-7.

12. Hurley J, Franco S, Gomez-Fernandez C et al. Breast cancer and human immunodeficiency virus: a report of 20 cases. Clin Breast Cancer 2001; 2:215-20; discussion 221.

13. Ashraff Z, Nallamala S. Breast cancer in a woman with HIV/AIDS: case report and review of literature. J HIV Ther 2007; 12:71-2.

14. El-Rayes BF, Berenji K, Schuman P, Philip PA. Breast cancer in women with human immunodeficiency virus infection: implications for diagnosis and therapy. Breast Cancer Res Treat 2002; 76:111-6.

15. INCA. Estimativas 2008: Incidência do Câncer no Brasil. Coordenação de Prevenção e Vigilância do Câncer. Instituto Nacional do Câncer. Secretaria de Atenção à Saúde. Ministério da Saúde. Brasil. Rio de Janeiro, 2007.

16. Brito C, Portela MC, Vasconcellos MT. Survival of breast cancer women in the state of Rio de Janeiro, Southeastern Brazil. Rev Saude Publica 2009; 43:481-9.

17. Rezende MC, Koch HA, Figueiredo Jde A, Thuler LC. Factors leading to delay in obtaining definitive diagnosis of suspicious lesions for breast cancer in a dedicated health unit in Rio de Janeiro. Rev Bras Ginecol Obstet 2009; 31:75-81.

18. Grinsztejn B, Bastos FI, Veloso VG, Friedman RK, Pilotto JH, Schechter M, Derrico M, Andrade A, Lourenco MC et al. Assessing sexually transmitted infections in a cohort of women living with HIV/AIDS, in Rio de Janeiro, Brazil. Int J STD AIDS 2006; 17:473-8.
19. Grinsztejn B, Veloso VG, Levi JE et al.. Factors associated with increased prevalence of human papillomavirus infection in a cohort of HIV-infected Brazilian women. Int J Infect Dis 2009; 13:72-80.

20. Luz PM, Velasque L, Friedman RK et al. Cervical cytological abnormalities and factors associated with high-grade squamous intra-epithelial lesions among HIV-infected women from Rio de Janeiro, Brazil. Int J STD AIDS. Accepted.

21. Chiao EY, Krown SE. Update on non-acquired immunodeficiency syndrome-defining malignancies. Curr Opin Oncol 2003; 15:389-97.

22. Shiels MS, Cole SR, Kirk GD, Poole C. A meta-analysis of the incidence of non-AIDS cancers in HIV-infected individuals. J Acquir Immune Defic Syndr 2009; 52:611-22.

23. Frisch M, Biggar RJ, Engels EA, Goedert JJ. Association of cancer with AIDS-related immunosuppression in adults. JAMA 201; 285:1736-45.

24. Amir H, Kaaya EE, Kwesigabo G, Kiitinya JN. Breast cancer before and during the AIDS epidemic in women and men: a study of Tanzanian Cancer Registry Data 1968 to 1996. J Natl Med Assoc 2000; 92:301-5.

25. Hessol NA, Seaberg EC, Preston-Martin S et al. Cancer risk among participants in the womens interagency HIV study. J Acquir Immune Defic Syndr 2004; 36:978-85.

26. Pantanowitz L, Dezube BJ. Reasons for a deficit of breast cancer among HIV-infected patients. J Clin Oncol 2004; 22:13478; author reply 1349-50.

27. Morgan J, Gladson J, Rau K. Position paper of the American council on science and health on risk factors for breast cancer: established, speculated, and unsupported. The Breast Journal 1998; 4:177-97.

28. Lester J. Breast cancer in 2007: incidence, risk assessment, and risk reduction strategies. Clin J Oncol Nurs 2007; 11:619-22.

29. Richards MA, Westcombe AM, Love SB, Littlejohns P, Ramirez AJ. Influence of delay on survival in patients with breast cancer: a systematic review. Lancet 1999; 353:1119-26.

30. Anyanwu SN. Temporal trends in breast cancer presentation in the third world. J Exp Clin Cancer Res 2008; 27:17.

31. Thuler LC, Mendonça G, 2005. Initial staging of breast and cervical cancer in Brazilian women. Rev Bras Ginecol Obstet 27: 650-660

32. Gebrim LH. Breast cancer screening and stage at diagnosis. Rev Bras Ginecol Obstet 2009; 31:216-8.

33. Preston-Martin S, Kirstein LM, Pogoda JM et al. Use of mammographic screening by HIV-infected women in the Womens Interagency HIV Study (WIHS). Prev Med 2002; 34:386-92. 